\title{
ANALYSIS OF CYLINDRICAL SHELL STRUCTURE WITH VARYING PARAMETERS
}

\author{
Nilesh S. Lende ${ }^{1}$, Rajshekhar S. Talikoti ${ }^{2}$ \\ ${ }^{1} P G$ student, Department of Civil Engineering, Late G. N. Sapkal College of Engineering, Anjaneri Nashik-422413, \\ Affiliated to Pune University, India. \\ ${ }^{2}$ Professor \& Head, Department of Civil Engineering, Late G. N. Sapkal College of Engineering, Anjaneri Nashik- \\ 422413, Affiliated to Pune University, India.
}

\begin{abstract}
The shell structures are composed of a thin shell made of reinforced concrete without the use of internal columns giving an open interior. Most common shells used in industry are flat plates and domes but different shapes like cylindrical, parabolic or spherical section may also used. Sports or storage facilities buildings are common concrete shell structures. However, they can be difficult to design, as the exact shape required for stability of structure depends on the material used, the size of the shell, exterior or interior loading, and other oblique. So by varying the parameter of the shell, behaviour of the shell is also varying. Main goal of this paper is parametric analysis of the multiple cylindrical shell structures with different lengths. For analysis we took two different lengths of cylindrical shell and then, two parameters have been change first one is radius and second is thickness, on the basis of different radius and thickness for same chord width, length, and material of shell we will compare the behaviour of shell for different models.
\end{abstract}

Keywords: Multiple cylindrical shells, Analysis, Different Parameter.

\section{INTRODUCTION}

The reinforced concrete shells can be defined as curved shape slabs whose thickness is very small compared to their other dimensions. The curved structures resisted more applied forces than flat plate with less deformation and stresses. Also shell structure are much efficient than other structure having the same span and dimensions because there shapes have a high strength to weight ratio. There are a different type of shell depend upon their size, shape, type of load, material used etc. Due to this large variation, many practical difficulties were occurring. To solve these difficulties many researchers introduced their theory for design of shell. The common type of shell used in field is cylindrical reinforced concrete shell to cover large space. Generally long shells and short shells are the two different form of cylindrical shell. Normally long shells are used for roof factories and short shells for aircraft hangers.

In this paper we use thin reinforced concrete long cylindrical shell for analysis. Membrane analysis of circular cylindrical shells is very easy. For bending analysis of these shells, various researchers have presented different methods and equations. And these equations are very useful for deriving computer based solutions. The ASCE, manual 31 on design of concrete shell roofs method presents a method similar to that we are familiar with and use for elementary analysis of indeterminate structure in theory of structures. It will give us a good idea of the nature of the forces in these shells so that when we use the modern computer software, we can have a better awareness of the output. But the ASCE manual 31 tables are restricted to be used for limited shell dimensions only. Due to these restrictions we should always plan shells in such a way that their dimensions suit the tables of manual no. 31. But practically it will not possible always to plan shells according to manual no. 31 . So that we will analyses the multiple cylindrical shell for different parameters by using computer analysis program SAP. By varying the parameters of the shell, behavior of the shell is also varying. To know the behavior of the shell, we will take two different dimensions of models whose length to width ratio is 3 . In those models two parameters have been change; first one is radius and second is thickness. After analysis we will compare the behavior of the shells for different dimensions models.

\section{METHODS OF ANALYSIS}

A thin elastic shell resists the external load by developing direct forces and bending moments. For a given geometry of shell under some appropriate loading and support conditions, it is possible that they can be safety neglected. In such a case, the shell will resist the external forces through direct or membrane forces. The shell is then said to be under a membrane state of stress. The membrane theory is much simpler as compared to the bending theory, since in this theory, the membrane forces can be directly determined from equilibrium. Because of its simplicity, the membrane theory is often used as a reasonable basis for design. The membrane analysis would give forces along the longitudinal edges, which cannot be normally attained in practice by providing a suitable support. Any corrective force or displacement applied along these edges, so as to satisfy the actual support condition, would lead to bending of the shell. Hence, most of the cylindrical shell roof structures have to be analysed considering bending, to get a more realistic picture of force distribution in the shell. 


\section{DETAILS OF MODELS}

For analysis, following dimensions are considered which is tabulated in tables. Properties and dimensions of multiple cylindrical shells which are same for all models are shown in table 1.

Table 1: Structural Properties and Dimensions of all Models

\begin{tabular}{|l|l|}
\hline Live load & $0.60 \mathrm{KN} / \mathrm{m} 2$ \\
\hline Grade of Concrete & $\mathrm{M}-25$ \\
\hline Type of Steel & HYSD bars \\
\hline Column Height & $5.0 \mathrm{~m}$ \\
\hline Column Size & $1.0 \mathrm{~m} \mathrm{X} 0.5 \mathrm{~m}$ \\
\hline $\begin{array}{l}\text { Column Support } \\
\text { condition }\end{array}$ & Fixed \\
\hline Beam Size & $1.8 \mathrm{~m} \mathrm{x} 0.3 \mathrm{~m}$ \\
\hline Number of bay & 3 bay \\
\hline
\end{tabular}

Different parameters of multiple cylindrical shell models of type A, type A', type B and type B' are tabulated in table 2, table 3 , table 4 and table 5 respectively.

Table 2: Parameters of Type A models

\begin{tabular}{|l|l|l|l|l|l|}
\hline \multicolumn{6}{|l|}{ TYPE A } \\
\hline $\begin{array}{l}\text { Mod } \\
\text { el }\end{array}$ & $\begin{array}{l}\text { Span in } \\
\text { X } \\
\text { directio } \\
\mathrm{n}\end{array}$ & $\begin{array}{l}\text { Span in } \\
\text { Y } \\
\text { directio } \\
\mathrm{n}\end{array}$ & $\begin{array}{l}\text { Angle } \\
\begin{array}{l}\text { in } \\
\text { degre } \\
\mathrm{e}\end{array}\end{array}$ & $\begin{array}{l}\text { Radiu } \\
\mathrm{s}\end{array}$ & $\begin{array}{l}\text { Thickn } \\
\text { ess }\end{array}$ \\
\hline $\mathrm{A} 1$ & 30 & 10 & 30 & 10 & 0.075 \\
\hline $\mathrm{A} 2$ & 30 & 10 & 35 & 8.71 & 0.075 \\
\hline $\mathrm{A} 3$ & 30 & 10 & 40 & 7.77 & 0.075 \\
\hline $\mathrm{A} 4$ & 30 & 10 & 45 & 7.07 & 0.075 \\
\hline
\end{tabular}

Table 3: Parameters of Type A' models

\begin{tabular}{|l|l|l|l|l|l|}
\hline \multicolumn{6}{|l|}{ TYPE A' } \\
\hline $\begin{array}{l}\text { Mod } \\
\text { el }\end{array}$ & $\begin{array}{l}\text { Span in } \\
\text { X } \\
\text { directio } \\
\mathrm{n}\end{array}$ & $\begin{array}{l}\text { Span in } \\
\text { Y } \\
\text { directio } \\
\mathrm{n}\end{array}$ & $\begin{array}{l}\text { Angle } \\
\phi \text { in } \\
\text { degree }\end{array}$ & $\begin{array}{l}\text { Radiu } \\
\text { s }\end{array}$ & $\begin{array}{l}\text { Thickn } \\
\text { ess }\end{array}$ \\
\hline A11 & 40 & 13.33 & 30 & 13.33 & 0.075 \\
\hline A22 & 40 & 13.33 & 35 & 11.62 & 0.075 \\
\hline A33 & 40 & 13.33 & 40 & 10.37 & 0.075 \\
\hline A44 & 40 & 13.33 & 45 & 9.425 & 0.075 \\
\hline
\end{tabular}

Table 4: Parameters of Type B models

\begin{tabular}{|l|l|l|l|l|l|}
\hline \multicolumn{6}{|l|}{ TYPE B } \\
\hline $\begin{array}{l}\text { Mod } \\
\text { el }\end{array}$ & $\begin{array}{l}\text { Span in } \\
\text { X } \\
\text { directio } \\
\mathrm{n}\end{array}$ & $\begin{array}{l}\text { Span in } \\
\text { Y directio } \\
\mathrm{n}\end{array}$ & $\begin{array}{l}\text { Angle } \\
\phi \text { in } \\
\text { degree }\end{array}$ & $\begin{array}{l}\text { Radiu } \\
\text { s }\end{array}$ & $\begin{array}{l}\text { Thickn } \\
\text { ess }\end{array}$ \\
\hline B1 & 30 & 10 & 35 & 8.71 & 0.070 \\
\hline B2 & 30 & 10 & 35 & 8.71 & 0.075 \\
\hline B3 & 30 & 10 & 35 & 8.71 & 0.080 \\
\hline B4 & 30 & 10 & 35 & 8.71 & 0.100 \\
\hline
\end{tabular}

Table 5: Parameters of Type B' models

\begin{tabular}{|l|l|l|l|l|l|}
\hline \multicolumn{6}{|l|}{ TYPE B' } \\
\hline $\begin{array}{l}\text { Mode } \\
1\end{array}$ & $\begin{array}{l}\text { Span in } \\
\text { X } \\
\text { directio } \\
\mathrm{n}\end{array}$ & $\begin{array}{l}\text { Span in } \\
\text { Y } \\
\text { directio } \\
\mathrm{n}\end{array}$ & $\begin{array}{l}\text { Angle } \\
\phi \text { in } \\
\text { degre } \\
\mathrm{e}\end{array}$ & $\begin{array}{l}\text { Radiu } \\
\mathrm{s}\end{array}$ & $\begin{array}{l}\text { Thicknes } \\
\mathrm{s}\end{array}$ \\
\hline B11 & 40 & 13.33 & 35 & 11.62 & 0.070 \\
\hline B22 & 40 & 13.33 & 35 & 11.62 & 0.075 \\
\hline B33 & 40 & 13.33 & 35 & 11.62 & 0.080 \\
\hline B44 & 40 & 13.33 & 35 & 11.62 & 0.100 \\
\hline
\end{tabular}

From table 2 and table 3, type A and type A' models have same thickness with different radius of different lengths. And similarly from table 4 and table 5, type B and type B' models have same radius with different thicknesses of different lengths.

\section{ANALYSIS RESULT}

The main objective of this study is comparing the parametric analysis of multiple cylindrical shell structure with different lengths using analysis software SAP 2000. The linear static analysis is used because we consider only dead and live load on a multiple cylindrical shell. Stresses, Moment developed per unit lengths and Forces acting per unit length on the surface of shells are obtained from analysis by varying thickness and radius for different lengths.

For comparison of multiple cylindrical shells, we will separate models in two different conditions.

1. Taking models having same thickness with different radius and

2. Taking models having same radius with different thickness for maximum moment, maximum forces and maximum stresses which are presented below.

\subsection{Maximum Element Moments}

Figure 1 shows moment variation diagram and blue color indicates the portion of maximum moment on the surface of shell.

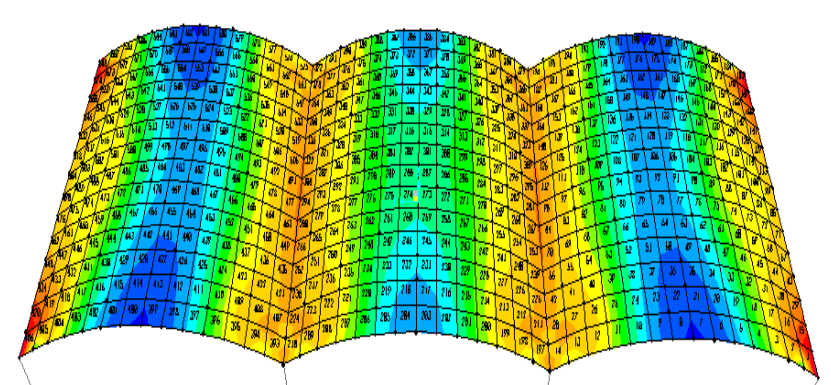

Fig 1: Moment variation diagram

\subsubsection{Take Models Having Same Thickness with Different Radius}

\subsubsection{Type A and Type A' Models}

Maximum moment value for type $A$ and type $A^{\prime}$ are tabulated in table 6 and shown in figure 2 . 
Table 6: Max. Moment value for Type A and Type A'

\begin{tabular}{|l|l|l|l|}
\hline \multicolumn{3}{|c|}{ SAME THICKNESS WITH DIFFERENT RADIUS } \\
\hline MODEL & $\begin{array}{l}\text { MAX. } \\
\text { MOMENT } \\
\text { IN KNm/m }\end{array}$ & MODEL & $\begin{array}{l}\text { MAX. } \\
\text { MOMENT } \\
\text { IN KNm/m }\end{array}$ \\
\hline A1 & 8 & A11 & 12 \\
\hline A2 & 7.5 & A22 & 14.3 \\
\hline A3 & 7 & A33 & 16.5 \\
\hline A4 & 8.8 & A44 & 12 \\
\hline
\end{tabular}

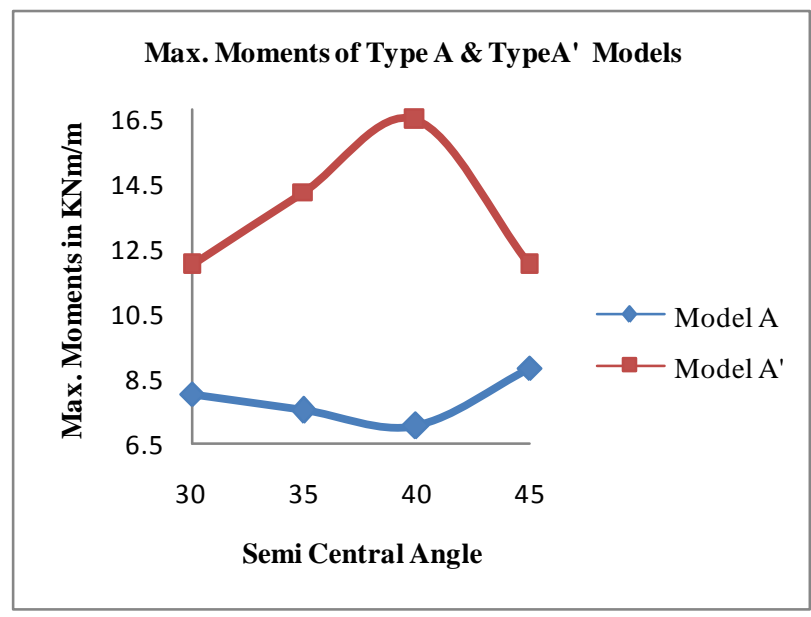

Fig 2: Comparison of Max. Moments for Type A Models \& Type A' Models

\subsubsection{Take Models Having Same Radius with Different Thickness}

\subsubsection{Type B and Type B' Models}

Maximum moment value for type B and type B' are tabulated in table 7 and shown in figure 3

Table 7: Max. Moment value for Type B and Type B'

\begin{tabular}{|l|l|l|l|}
\hline \multicolumn{3}{|c|}{ SAME RADIUS WITH DIFFERENT THICKNESS } \\
\hline MODEL & $\begin{array}{l}\text { MAX. } \\
\text { MOMENT } \\
\text { IN KNm/m }\end{array}$ & MODEL & $\begin{array}{l}\text { MAX. } \\
\text { MOMENT } \\
\text { IN KNm/m }\end{array}$ \\
\hline B1 & 6.5 & B11 & 12.1 \\
\hline B2 & 7.5 & B22 & 14.3 \\
\hline B3 & 8.5 & B33 & 13 \\
\hline B4 & 13.5 & B44 & 24 \\
\hline
\end{tabular}

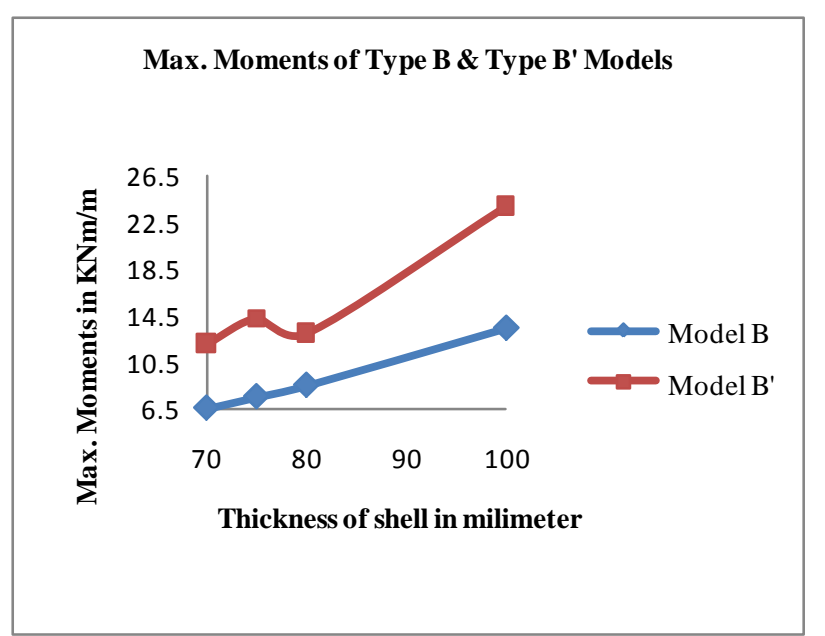

Fig 3: Comparison of Max. Moments for Type B Models \& Type B' Models

\subsection{Maximum Element Forces}

Figure 4 shows force variation diagram and blue color indicates the portion of maximum forces on the surface of shell.

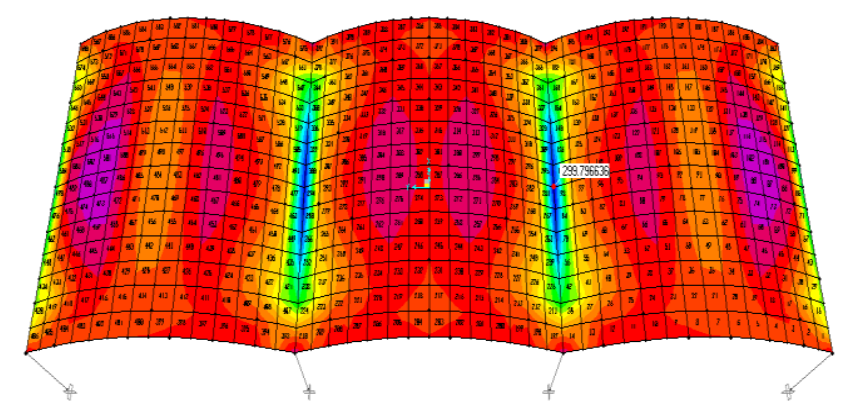

Fig 4: Force variation diagram

\subsubsection{Take Models Having Same Thickness with} Different Radius

\subsubsection{Type A and Type A' Models}

Maximum force value for type A and type A' are tabulated in table 8 and shown in figure 5 .

Table 8: Max. Forces value for Type A and Type A'

\begin{tabular}{|l|l|l|l|}
\hline \multicolumn{2}{|l}{$\begin{array}{l}\text { SAME THICKNESS } \\
\text { RADIUS }\end{array}$} \\
\hline MODEL & $\begin{array}{l}\text { MAX. } \\
\text { FORCE } \\
\text { IN KN/m }\end{array}$ & MODEL & $\begin{array}{l}\text { MAX. } \\
\text { FORCE } \\
\text { IN KN/m }\end{array}$ \\
\hline A1 & 187 & A11 & 350 \\
\hline A2 & 176 & A22 & 350 \\
\hline A3 & 176 & A33 & 300 \\
\hline A4 & 165 & A44 & 234 \\
\hline
\end{tabular}




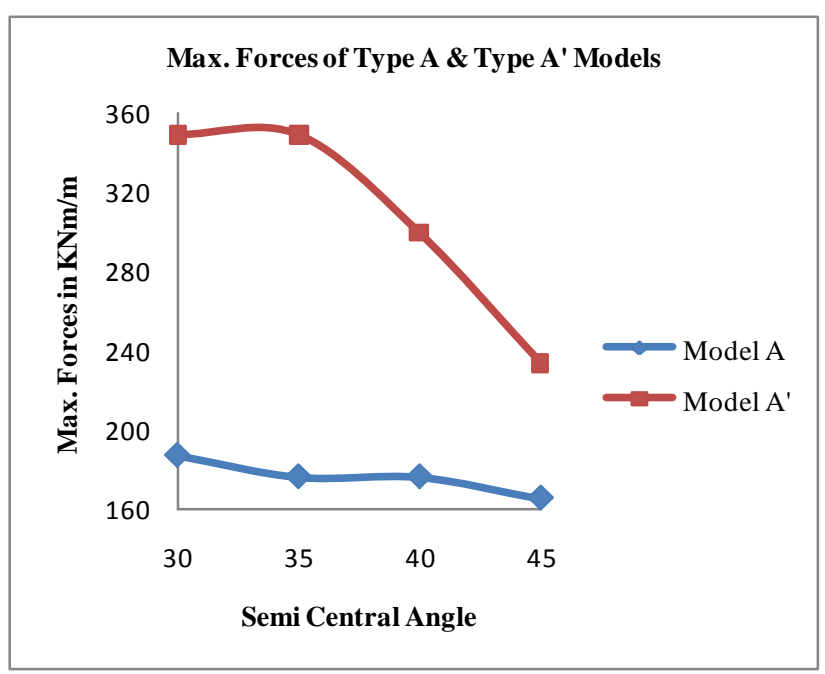

Fig 5: Comparison of Max. Forces for Type A Models \& Type A'Models

\subsubsection{Take Models Having Same Radius with Different Thickness}

\subsubsection{Type B and Type B' Models}

Maximum force value for type B and type B' are tabulated in table 9 and shown in figure 6.

Table 9: Max. Forces value for Type B and Type B'

\begin{tabular}{|l|l|l|l|}
\hline \multicolumn{3}{|c|}{ SAME RADIUS WITH DIFFERENT THICKNESS } \\
\hline MODEL & $\begin{array}{l}\text { MAX. } \\
\text { FORCE IN } \\
\text { KN/m }\end{array}$ & MODEL & $\begin{array}{l}\text { MAX. } \\
\text { FORCE IN } \\
\text { KN/m }\end{array}$ \\
\hline B1 & 176 & B11 & 300 \\
\hline B2 & 176 & B22 & 350 \\
\hline B3 & 198 & B33 & 350 \\
\hline B4 & 275 & B44 & 550 \\
\hline
\end{tabular}

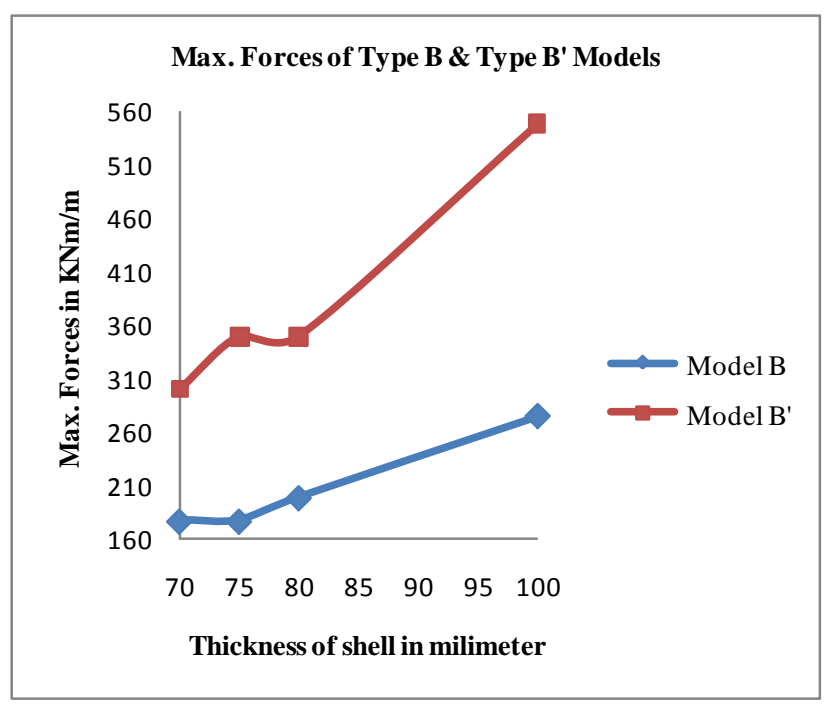

Fig 6: Comparison of Max. Forces for Type B Models \& Type B' Models

\subsection{Maximum Element Stresses}

Figure 7 shows stress variation diagram and blue color indicates the portion of maximum stresses on the surface of shell.

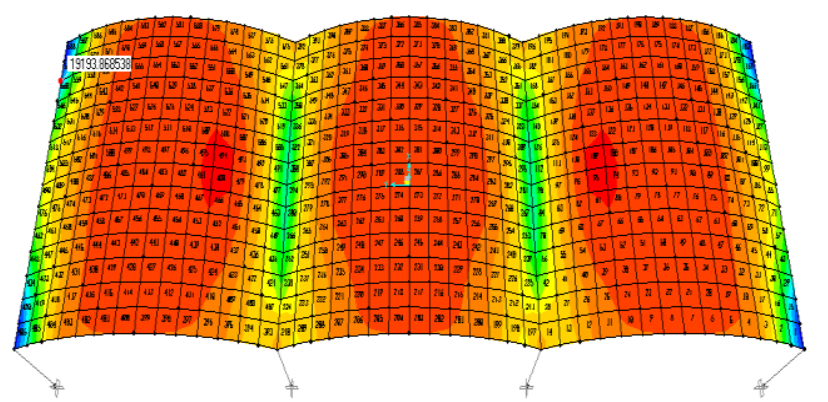

Fig 7: Stress variation diagram

\subsubsection{Take Models Having Same Thickness with Different Radius}

\subsubsection{Type A and Type A' Models}

Maximum stresses value for type A and type A' are tabulated in table 10 and shown in figure 8.

Table 10: Max. Stresses value for Type A and Type A'

\begin{tabular}{|c|c|c|c|}
\hline $\begin{array}{l}\text { SAME } \\
\text { RADIUS }\end{array}$ & THICKNESS & WITH & DIFFERENT \\
\hline MODEL & $\begin{array}{l}\text { MAX. } \\
\text { STRESSES } \\
\text { IN KN/m² }\end{array}$ & MODEL & $\begin{array}{l}\text { MAX. } \\
\text { STRESSES } \\
\text { IN KN/m² }\end{array}$ \\
\hline A1 & 13120 & A11 & 18120 \\
\hline $\mathrm{A} 2$ & 14320 & A 22 & 19842 \\
\hline A 3 & 11023 & A33 & 17385 \\
\hline A4 & 11080 & A44 & 22120 \\
\hline
\end{tabular}

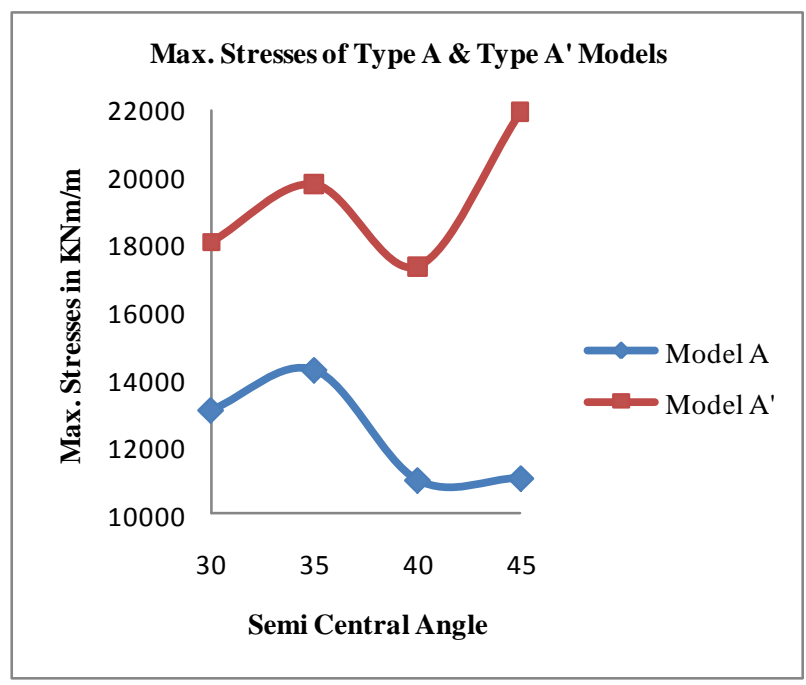

Fig 8: Comparison of Max. Stresses for Type A Models \& Type A' Models 


\subsubsection{Take Models Having Same Radius with Different Thickness}

\subsubsection{Type B and Type B' Models}

Maximum stresses value for type B and type B' are tabulated in table 11 and shown in figure 9.

Table 11: Max. Stresses value for Type B and Type B'

\begin{tabular}{|l|l|l|l|}
\hline \multicolumn{2}{|c|}{ SAME RADIUS WITH DIFFERENT THICKNESS } \\
\hline MODEL & $\begin{array}{l}\text { MAX. } \\
\text { STRESSES } \\
\text { IN KN/m }\end{array}$ & MODEL & $\begin{array}{l}\text { MAX. } \\
\text { STRESSES } \\
\text { IN KN/m }\end{array}$ \\
\hline B1 & 12120 & B11 & 17052 \\
\hline B2 & 14320 & B22 & 19850 \\
\hline B3 & 12200 & B33 & 18115 \\
\hline B4 & 14312 & B44 & 20913 \\
\hline
\end{tabular}

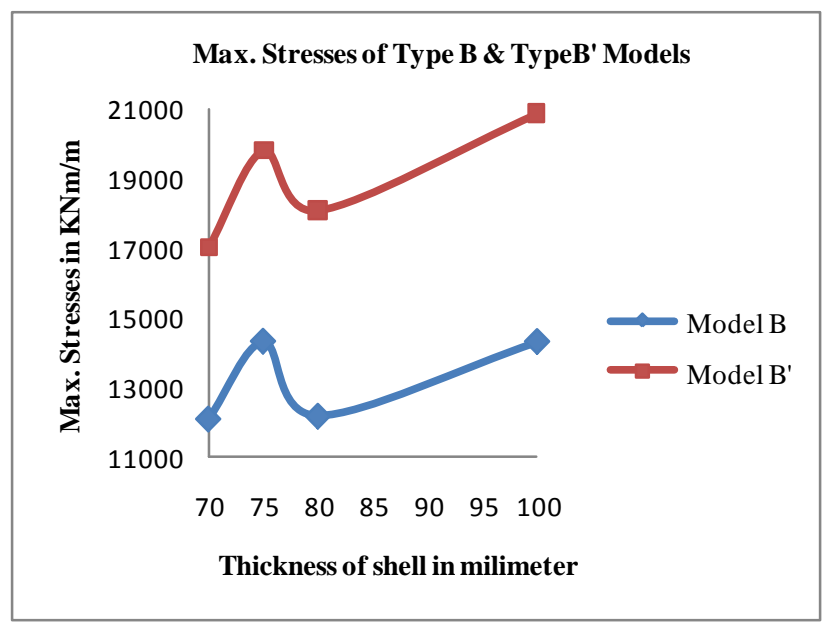

Fig 9: Comparison of Max. Stresses for Type B Models \& Type B' Models

\section{DISCUSSION}

\subsection{For Maximum Forces}

1. From Figure 5, it is observed that if a type of models having same thickness and different radius, then the maximum forces value decreases with increased in semi central angle for Type A and Type A' models.

2. From figure 6 , it is observed that if a type of models having same radius and different thickness, then the maximum forces value increases with increase in thickness for Type B and Type B' models. But certain reduction is occurred at $80 \mathrm{~mm}$ thickness due to change in dimensions of shell in Type B' models.

\subsection{For Maximum Stresses}

1. From Figure 8 , it is observed that if a type of models having same thickness and different radius, then the maximum stresses value decreases with increase in semi central angle for Type A and Type A' models up to 40 degree and then again increased.
2. From figure 9, it is observed that if a type of models having same radius and different thickness, then the maximum Stresses value increases with increase in thickness for Type B and Type B' models. But certain reduction is occurred at $80 \mathrm{~mm}$ thickness due to change in dimensions of shell in both Type B and Type B' models.

\subsection{For Maximum Moments}

1. From Figure 2, it is observed that if a type of models having same thickness and different radius, then the maximum moment's value decreases with increase in semi central angle for Type A up to 40 degree and then again increased. For Type A' Models, maximum moments value increases with increasing semi central angle up to 40 degree and then again decrease.

2. From figure 3, it is observed that if a type of models having same radius and different thickness, then the maximum moment value increases with increase in thickness for Type B and Type B' models. But certain reduction is occurred at $80 \mathrm{~mm}$ thickness due to change in dimensions of shell in Type B' models.

3. The surface of maximum moment formed at the middle end of the end shell but due to increase in length and width of shell, the portion of maximum moments for some models formed at that surface where two shells are joining with each other at end. Which means direct forces exerted by the end of the shell at its supports was not distributed properly. To overcome this problem, we provided stiffener beam along the curve edge of a shell. So analysis of multiple cylindrical shell structure with stiffener beam is carried out.

\subsection{Analysis of Multiple Cylindrical Shells with Stiffener Beam}

The supports provided on edge of a shell along the curve are called as Stiffener. Comparison of analysis of multiple cylindrical shell structure with and without stiffener beam is shown in figure 10 to figure 12 .

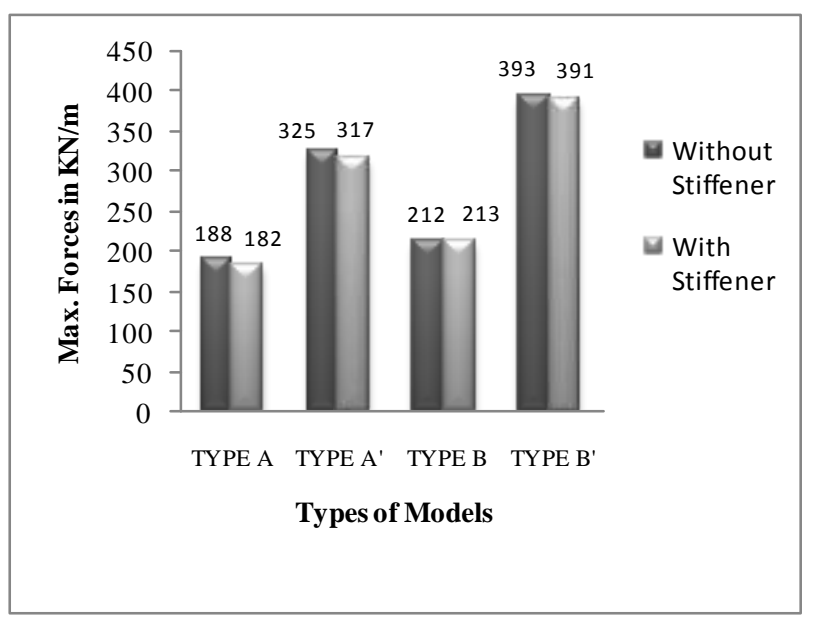

Fig 10 Variation of forces due to stiffener beam 


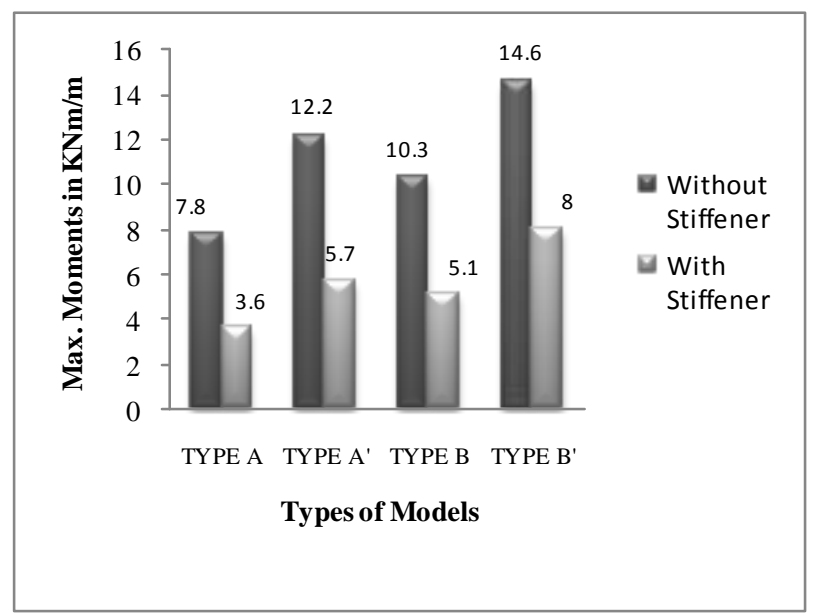

Fig 11 Variation of moments due to stiffener beam

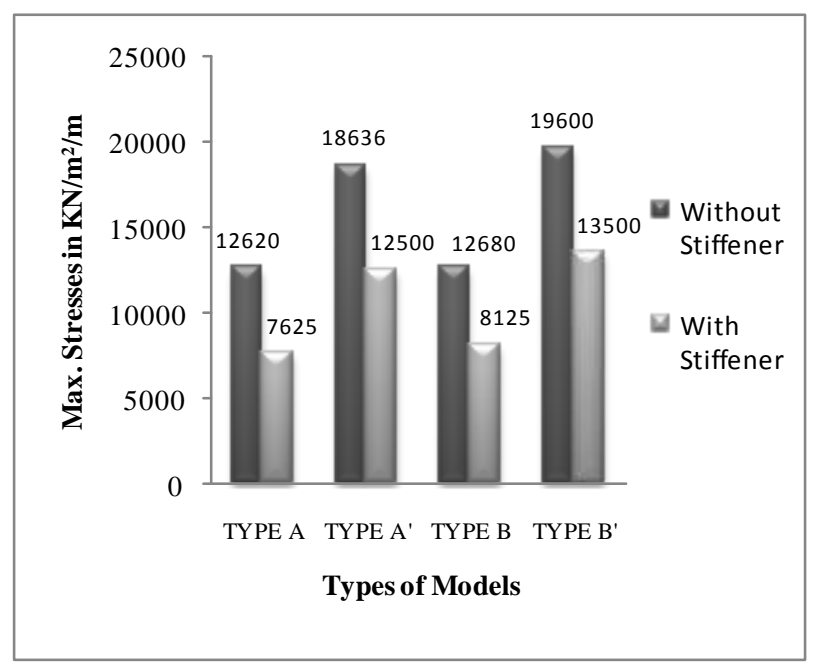

Fig 12: Variation of stresses due to stiffener beam

\section{CONCLUSION}

From the analysis of multiple cylindrical reinforced concrete shell structure with varying parameters following conclusions can be drawn.

1. The behavior of reinforced concrete multiple cylindrical shell structure whose length to width ratio is three was different for different dimensional models.

2. Moments and Stresses of cylindrical shell structure are significant when the semi central angle is 40 degree and thickness of shell is $80 \mathrm{~mm}$.

3. Stiffener beams transferred the tension and moment created by the shear from the shell on to the support.

4. Hence stiffener beams is an essential part of a multiple cylindrical reinforced concrete shell structure.

\section{REFERENCES}

[1] Chandrasekaran S., Ashutosh Srivastava, Parijat Naha. 2005. "Computational tools for shell structures" Proc. of Intl. conf. on structures and road transport (START-2005), IIT-Kharagpur, India, pp. 167-175.

[2] Ramaswamy G.S. 1968. "Design and construction of concrete shell roof” First Edition, Mc-Graw Hill.
[3] Timoshenko, S.P., Woinowsky-Krieger, S. 1959. "Theory of Plates and Shells" 2d ed., McGraw-Hill Book Company, New York.

[4] Dr. Umesh Pendharkar, Ravindra Rai, 2012. "Computer Aided Analysis of Multiple Cylindrical Shell Structure Using Different Parameters". (IJERT) Vol. 1 Issue 3, May - 2012 ISSN: 22780181

[5] Srinivasan Chandrasekaran1*, S.K.Gupta2, Federico Carannante3,2009. "Design aids for fixed support reinforced concrete cylindrical shells under uniformly distributed loads". International Journal of Engineering, Science and Technology Vol. 1, No. 1, 2009, pp. 148-171

[6] Varghese P.C.2014. "Design of Reinforced Concrete Shells and Folded Plates" First Edition, PHI Learning Private Limited, Delhi.

[7] IS-2210-1988, "Criteria for Design of Reinforced Concrete Shell Structures and Folded Plates", B.I.S., New Delhi.

[8] Bandyopadhyay J.N.,1998. "Thin Shell Structures Classical and Modern Analysis", New Age International Publishers, New Delhi.

[9] Chandrashekara K.,1986. "Analysis of Thin Concrete Shells", Tata McGraw Hill, New Delhi.

[10] "Design of Cylindrical Concrete Shell Roof", Manual No. 31, ASCE, New York, 1952 